\title{
Action of Ship Waves on a Verticial Cylinder in front of a Vertical Wall
}

\author{
L. Sun ${ }^{1 *}$, Z. Zong ${ }^{2}$, G. H. Dong ${ }^{1}$
}

${ }^{1}$ State Key Laboratory of Coastal and Offshore Engineering, Dalian University of Technology, Liaoning, 116024 China

${ }^{2}$ Department of Naval Architecture, Dalian University of Technology, Liaoning 116024, China

Errail: slsunlei1982@163.com

\begin{abstract}
In this paper, the action of ship waves on a nearby vertical cylinder in front of an infinite vertical wall is evaluated. The problem contains two separate problems: evaluation of waves generated by a moving ship (ship-wave problem) and evaluation of the action of ship waves on a cylinder in front of the infinite wall (wave-action problem). To solve the ship-wave problem, the thin-ship theory is employed. To solve the wave-action problem, a boundary element method is developed. The two methods are combined to solve the problem in this paper. Based on the image principle, the hydrodynamic problem of a cylinder in front of a vertical wall is transformed into the equivalent problem of double cylinders in unbounded fluid domain. The resultant forces and moments acting on the cylinder are surprisingly large, characterized by being highly oscillatory. The periods of the oscillations are proportional to ship speed. It is shown that wave forces of the cylinder in front of a vertical wall are evidently different from those in case of cylinder in unbounded fluid domain. Meanwhile, the potential fatigue damage resulting from oscillations of the forces and moments should be considered, too.
\end{abstract}

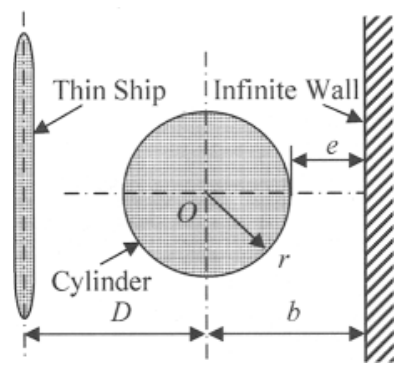

Figure: Sketch of the cylinder in front of the infinite wall

\section{REFERENCES}

1. Cheng T Z, Shi Z K. Theory of Ship Wave Making Resistance and its Application in Ship Design. Huazhong University Press. 1987; 72-76

2. Bai W, Teng B. Second-order wave diffraction around 3-d bodies by a time-domain method. China Ocean Engineering, 2001; 15(1): 73-85

3. Teng B, Ning D Z, Zhang X T. Wave radiation by a uniform cylinder in front of a vertical wall. Ocean Engineering, 2004; 31: 201-224 